\title{
Medicalização, diagnóstico clínico e queixa-conduta - redes de significação em jogo
}

\author{
Medicalization, clinical diagnosis, and "treat and street" \\ - networks of meaning at stake (abstract: p. 13)
}

Medicalización, diagnóstico clínico y queja-conducta

- redes de significación en juego (resumen: p. 13)

\section{Karla Amorim Sancho(a)}

<k178883@dac.unicamp.br>

Claudia Regina Castellanos Pfeiffer ${ }^{(b)}$
$<$ claupfe@gmail.com> (iD)

Carlos Roberto Silveira Corrêa ${ }^{(\mathrm{c})}$

<ccorrea@fcm.unicamp.br>

\section{Artigos}

\author{
Pós-Graduanda do Departamento \\ de Saúde Coletiva (Doutorado), \\ Faculdade de Ciências Médicas (FCM), \\ Universidade Estadual de Campinas \\ (Unicamp). Rua Tessália Vieira de \\ Camargo, 126, Cidade Universitária \\ Zeferino Vaz. Campinas-SP, Brasil. \\ 13083-887. \\ (b) Laboratório de Estudos Urbanos, \\ Unicamp. \\ (c) Departamento de Saúde Coletiva, FCM, \\ Unicamp.
}

Este artigo faz emergir uma rede discursiva entre o processo de medicalização, o funcionamento discursivo do diagnóstico clínico na contemporaneidade e um funcionamento particular de clínica médica sustentado por um atendimento do tipo queixa-conduta. Empreendendo uma Análise Discursiva, percorremos movimentos de sentido constitutivos da história da palavra 'diagnóstico', realizando um gesto analítico que retoma suas condições de produção e funcionamento na atualidade, explicitando efeitos da medicalização. Abordamos o atendimento queixa-conduta, no qual a posição-sujeito médico se insere em condições de produção para que o fármaco assuma o lugar da autoria na relação médicopaciente, impactado pelo próprio funcionamento do diagnóstico na atualidade. Resulta que esse funcionamento do diagnóstico na prática clínica implica um silenciamento do laço social e político pressuposto nessa prática, o que permite o estabelecimento do fármaco como lugar de enunciação dos procedimentos que visem à saúde do paciente.

Palavras-chave: Análise de discurso. Medicalização. Diagnóstico. Queixa-conduta. Saúde Coletiva. 


\section{A Análise de Discurso}

Para a Análise de Discurso (AD) o discurso é o efeito de sentido entre locutores. Em nosso caso, o diagnóstico é compreendido como um discurso próprio do espaço da saúde, que tem como locutores o médico e o mundo que nos cerca e que, portanto, produz efeito de sentidos entre os locutores (paciente, familiares, gestão pública, Estado, Ministério da Saúde). Nessa relação, o médico ocupa a função-autor ${ }^{(\mathrm{d})}$, formulando um diagnóstico e/ou conduta e apresentando-a ao seu paciente, à família do paciente e à sociedade como locutores leitores desse discurso. Antes de prosseguir nesta direção, queremos situar mais a perspectiva da $\mathrm{AD}$.

Para a AD, o discurso é entendido como materialidade da ideologia que, por sua vez, não é um conteúdo ou valor, mas a direção política ${ }^{(e)}$ do sentido. Nessa perspectiva, os sentidos são histórico-socialmente construídos, numa dinâmica de disputa que resulta na estabilização de sentidos em formações discursivas ${ }^{(f)}$ - que ganham sentido porque derivam de um jogo definido pela formação ideológica dominante na conjuntura em que se inserem - distintas em relação de tensão, antagonismo e contradição no interior do interdiscurso ${ }^{(\mathrm{g})}$.

Desse modo, o sentido não é transparente, nem mais ou menos verdadeiro, mas histórico e polissêmico. É preciso ainda afirmar que a relação entre um dizer e suas condiçốes sócio-históricas não é secundária, mas constitutiva das próprias significações ${ }^{6}$. Por fim, é necessário ressaltar que, em todo processo de análise, o gesto de interpretação do analista é também afetado pela historicidade do discurso que compreende os enunciados quando os traz ao fio de seu próprio discurso.

Compreendemos 'diagnóstico' como uma forma material que - na sua ausência ou presença - pode nos indicar parte do processo de significação em funcionamento no atendimento clínico. Nosso trabalho realizou-se em torno da espessura semântica dessa forma material situada numa rede constituída por diferentes discursos: do Ministério da Saúde; lexicográfico; da crítica acadêmica ao atendimento do tipo queixa-conduta e ao diagnóstico que se restringe a uma categorização ou implica medicalização e/ ou patologização da sociedade. Nosso intuito foi o de analisar a presença/ausência de 'diagnóstico', sem tomá-lo em sua evidência. A partir dele, constituiu-se um pequeno arquivo, no gesto mesmo de fazer a análise.

Nesta perspectiva, explanaremos as condições de produçãao ${ }^{(\mathrm{h})}$ dos sentidos mais estabilizados para o diagnóstico e sua prática.

É a partir deste lugar teórico que nossas mediações serão feitas.

\section{Uma história da palavra diagnóstico: um gesto de análise}

De modo a compreender parte dos sentidos em jogo na relação com o diagnóstico, tomando-o como um discurso, faremos uma pequena trajetória na história ${ }^{(\mathrm{i})} \mathrm{da}$ palavra diagnóstico.

Para iniciar essa trajetória, lançaremos mão do dicionário, uma vez que, para a $\mathrm{AD}$ e para a lexicografia discursiva, podemos compreendê-lo como espaço de materialização de memórias do dizer das palavras, trazendo a representação da memória coletiva que legitima os usos sociais da língua, estabelecendo uma relação entre a norma linguística vigente e o momento histórico de uma dada sociedade ${ }^{7}$. (d) Discursivamente, "a função-autor se realiza toda vez que o produtor da linguagem se representa na origem, produzindo um texto com unidade, coerência, progressão, não contradição e fim. Ela se aplica ao corriqueiro da fabricação da unidade do dizer comum, afetada pela responsabilidade social"2 ( $p$. 69). "O autor responde pelo que diz ou escreve, pois é suposto estar em sua origem" ${ }^{\prime 3}$ (p. 65).

(e) O político é compreendido discursivamente como a divisão dos sentidos. Divisão esta sempre subsumida a relações de força. Portanto, a direção política do sentido é na $A D$ compreendida como o sentido que, nas relações de força vigentes, efetivase como aquele evidente e estabilizado por um processo ideológico.

(f) A formação discursiva é definida na sua relação com a formação ideológica: "As formações ideológicas [...] comportam necessariamente como um de seus componentes uma ou mais formações discursivas inter-relacionadas que determinam o que pode e deve ser dito (articulado sob a forma de uma arenga, de um sermão, de um panfleto, de uma exposição, de um programa, etc.) a partir de uma posição dada em uma conjuntura dada"4 (p. 32). 
Naquele que consultamos (Houaiss) ${ }^{8}$, verificamos que "diagnóstico" é definido tanto como a "taxonomia de uma doença" como "o processo desenvolvido para identificar e localizar a doença dentro dessa taxonomia”. Diagnóstico, portanto, se articula ao sentido de "classificação" e ao de "identificação/referência a algo já dado". Não estamos afirmando que esses seriam os únicos sentidos de diagnóstico, mas que esses são estabilizados socialmente, a ponto de constarem na definição lexicográfica.

Para a $\mathrm{AD}$, as palavras têm história e ela afeta os sentidos com que hoje nos relacionamos, no movimento das palavras. Daí a importância de estudar, também, a etimologia das palavras e a história que elas têm.

Faremos mais um gesto: diagnóstico é uma palavra composta por duas partículas de origem grega: dia, que significa através, e gnosis, que significa conhecer. Assim, outro sentido da palavra diagnóstico é "conhecer através" ou "através do conhecimento". Sigamos esta pista etimológica na relação com a história da medicina ${ }^{(j)}$.

Para os gregos, segundo Jaeger', seria por meio do conhecimento do mundo e dos fatos da vida do paciente que o médico o conheceria e formularia o seu diagnóstico. Já constava nos textos que constituem o Corpus Hipocratico que seria a partir dos sinais e dos sintomas que o médico chegaria ao diagnóstico: o sinal seria um indicativo da importância de o médico ver, através dos seus próprios sentidos, o que o paciente apresenta; e os sintomas seriam expressão peculiar da afecção da alma de que padece o paciente ${ }^{1}$. Essa lógica se consolida na relação entre anamnese, diagnóstico e prognóstico ${ }^{1}$.

Para Entralgo ${ }^{10}$, o Corpus Hipocratico associava o diagnóstico com o prognóstico, o substrato orgânico, a etiologia, e com a relação médico-paciente, que é única e determinada pelo tempo e local em que esta relação se dá. Segundo esse autor, outra escola médica grega - a de Cnydos - focava nos aspectos orgânicos da doença, na sua localização no corpo e em sua manifestação; por isso essa escola caracterizava-se por nomear doenças, tipificando-as ${ }^{11}$. Uma terceira escola foi a de Palermo, na Sićlilia, que se associou à de Cnydos, constituindo a escola médica sicílico-cnídica. Nela estudou Galeno, médico responsável pela leitura mais cuidadosa dos textos hipocráticos. Foi ele que cunhou a expressão diagnóstico científico e propôs que o diagnóstico deveria ser localizado e racional; deveria também basear-se nas estruturas do corpo. Para Galeno, eram três os pilares do saber médico: lógica, física e ética.

Segundo Marques ${ }^{12}$, Hipócrates e seus seguidores que escreveram o Corpus Hipocratico $(\mathrm{CH})$ são representantes da escola médica do Dogmatismo, assim como Galeno representa a escola médica do Empirismo. Para Entralgo ${ }^{10}$ (op. cit.), existe uma diferença entre o diagnóstico como descrito no $\mathrm{CH}$ e aquele proposto por Galeno: no hipocrático, o médico ia do "caso" para o "tipo", enquanto no galênico ele ia do "tipo" para o "caso".

Numa perspectiva discursiva, o médico que formula um diagnóstico filiado aos sentidos hipocráticos se constitui diferentemente de outro que formula um diagnóstico filiado aos sentidos galênicos. Esses discursos se constituem em formaçóes discursivas diferentes ${ }^{13}$.

Vale referenciar, ainda, a medicina islâmica - na qual se instalou o sentido de diagnóstico filiado a Galeno -, porque ela se tornou referência no Renascimento europeu e durante o mercantilismo, com Sydenham ${ }^{14}$, estabilizou-se e passou a significar "categorizar" / "identificar", sentidos encontrados nos dicionários atuais (do tipo para o caso) ${ }^{15}$. (g) "O interdiscurso é todo o conjunto de formulações feitas e já esquecidas que determinam o que dizemos. É preciso que o que foi dito por um sujeito específico, em um momento particular, se apague na memória para que, passando para o anonimato, possa fazer sentido em "minhas" palavras. Pelo funcionamento do interdiscurso, suprime-se, por assim dizer, a exterioridade como tal, para inscrevê-la no interior da textualidade" ${ }^{5}$ (p. 33).

(h) As condições de produção fazem parte da exterioridade constitutiva da língua e podem ser entendidas como condições de produção em sentido estrito (circunstâncias de enunciação) e em sentido amplo (contexto sócio-histórico-ideológico) 5 . Elas compreendem fundamentalmente os sujeitos e a situação, bem como a memória, que é constituída pelas possibilidades de significação de um dizer.

(i) Para a AD há sempre histórias. Isso porque há sempre disputas de sentidos e de narrativas. Nosso gesto faz um recorte nessas histórias, sem qualquer pretensão de completude ou universalidade.

(j) Lembrando sempre que há histórias, vamos fazer um trajeto possível sob uma narrativa disponível dentro da história da medicina. 
Nesse período histórico, o sentido que se estabiliza na relação entre o médico e a natureza tem suas condições de produção no mercantilismo: para o médico fazer um diagnóstico, ele deveria fazer uso de uma taxonomia e de uma identificação às quais o paciente pudesse ser ajustado, e que estas pudessem ser aplicadas em todos os locais, como uma mercadoria. Foi a partir de Sydenham ${ }^{14}$ (op. cit.), portanto, que se acentuou a tendência de diagnosticar indo do "tipo" para o "caso": os "casos" seriam adequados aos "tipos" previamente estabelecidos.

Cumpre destacar que, a partir da segunda metade do século XVIII ao final da primeira metade do século XIX, ocorreu um processo de transformação do saber e da prática médica ocidental: a concepção de doença passa a ser a categoria central. Quando a noção de localização da doença no corpo - nascida da anatomopatologia - associa-se à descoberta dos micro-organismos por Pasteur, as duas se constituem no cerne das definições das doenças infecciosas, e essa concepção ontológico-localista e mecânico-causal se expande para todo o universo das doenças dos humanos, resultando na constituição da entidade "doença”, a ser tratada especificamente ${ }^{16,17}$. A terapêutica é hierarquizada segundo sua capacidade de atingir as causas últimas das doenças. A própria definição de saúde, apesar dos inúmeros esforços em contrário, é assumida como a ausência de doenças ${ }^{18,19}$

De nosso lugar teórico - o da Análise de Discurso - todos esses sentidos que viemos trazendo à tela se constituem sob condiçôes de produção sócio-históricas e continuam a reverberar na memória discursiva. No entanto, é também na memória discursiva, e na relação de forças, que algum(ns) sentido(s) se faz(em) estável(is) e evidente(s). Para nós, é esse do Mercantilismo, filiado à memória discursiva configurada em Cnydos, com Galeno, que sustenta hoje, de modo hegemônico, a relação da prática clínica com os sentidos de diagnóstico, materializada no discurso lexicográfico: "taxonomia de uma doença" e "o processo desenvolvido para identificar e localizar a doença dentro dessa taxonomia”.

\section{O diagnóstico na atualidade: desdobramentos da medicalização}

Pudemos ver que há muitos sentidos na história dos sentidos de diagnóstico. Do lugar da $\mathrm{AD}$, esses sentidos não desaparecem. Eles continuam a funcionar na memória discursiva que configura sentidos possíveis para a formulação do diagnóstico. Assim, também os debates acadêmicos em torno do diagnóstico se formulam dentro dessa memória discursiva ${ }^{20}$.

É preciso considerar que, em termos de condições de produção dos sentidos mais estabilizados para o diagnóstico e sua prática, o desenvolvimento do conhecimento biomédico, os novos recursos - laboratoriais e de imagem - e a atual configuração social do trabalho são questôes preponderantes. Simultaneamente, podemos perceber que vários diagnósticos já definidos (taxonomia), como depressão e ansiedade, são cada vez mais discutidos em público. Essa conjuntura aumenta os possíveis efeitos de sentido da palavra diagnóstico e demandam do médico o seu posicionamento para o mundo; reinscrevem-se no próprio imaginário médico quando ele formula o diagnóstico. $\mathrm{Ou}$ seja, hoje, estamos diante - em função dessa memória discursiva explanada e de uma hegemonia da formação discursiva biomédica - de um sentido estabilizado de diagnóstico que sustenta o processo de medicalização presente de forma marcante na socie- 
dade atual: um nome de doença implica um nome de remédio para curar essa doença diagnosticada.

Nossa posição ética frente ao diagnóstico é distinta. Aderimos a uma das interpretações vigentes sobre o funcionamento do diagnóstico que é o de tomá-lo como uma narração ${ }^{21}$. No diagnóstico, o médico narra alguma coisa do paciente. E narra também alguma coisa de si - uma vez que só pode falar do paciente a partir de seu olhar - afetado já pelo olhar do outro sobre si e sobre ele. Filiamo-nos a uma formação discursiva hipocrática, em que diagnosticar é "conhecer através”: através de um olhar, de uma relação, de um acontecimento na clínica que não passa, necessariamente, por nomear uma doença. Na narrativa, o médico pode assumir o papel de autor, o de leitor, ou de ambos. O autor é responsável pelo texto. O leitor é responsável por fazer o texto público, ele o lê. Essa autoria/leitura é, para nós, a construção de um espaço de relação entre o médico, o paciente e seu entorno: conhecimento compartilhado, laço, responsabilidade pelo processo de estabelecimento da saúde na prática clínica. Diagnosticar não é somente dar nome a uma doença, mas estabelecer uma relação ética na direção de um conhecimento compartilhado que institui condiçôes de produção para que o paciente se encontre em uma posição saudável, sendo a referência do que é saudável construída na prática clínica de acordo com as possibilidades e sentidos compartilhados ${ }^{22}$.

No entanto, é o outro sentido que circula de modo transparente. E é esse outro sentido que associa diagnóstico ao nome de uma doença e ao nome de uma medicação que tem um papel central no estudo do fenômeno social chamado doença, seja ele considerado na clínica ou na coletividade ${ }^{21}$. Quando o adoecimento é possível de ser diagnosticado - enquadrado pela nosologia biomédica - a efetivação de sua cura ou controle está vinculada aos critérios diagnósticos e é esperada em conformidade com o estabelecimento da terapêutica padronizada respectiva ${ }^{22}$. E, nessa relação, é o Estado que fica responsável pelas estratégias de prevenção e por fornecer instrumentos necessários para a intervenção frente aos diagnósticos; ou seja, o Estado planeja as suas intervençóes a partir dos diagnósticos a ele apresentados. As açóes médicas geradas pelos diagnósticos são codificadas pelo Estado e, a partir delas e de suas codificaçóes, é feita a remuneração dos profissionais da saúde. Por isso concordamos com Porto ${ }^{1}$ quando ele afirma: "Podese dizer que o diagnóstico é a base da prática médica atual, em função do aparecimento de medicamentos específicos, de intervençốes cirúrgicas eletivas e da necessidade de prestar contas ao mundo que nos cerca"1 (p. 86).

Entendemos que é nessa direção de sentido que Rosenberg assevera que "o diagnóstico é indispensável para o médico"21 (p. 252); e Lana afirma que "o diagnóstico é o principal fundamento da arte médica e é nele que se consolidam, e estão centradas, todas as etapas do atendimento médico"23 (p. 273).

Decorrente desse sentido de categorização de doença, que proporciona a possibilidade de um crescimento da medicalização da sociedade, encontra-se no Brasil, conforme afirmam vários autores ${ }^{22,24,25}$, a prática de um atendimento do tipo queixa-conduta, na qual o médico não formula o diagnóstico, nem para o paciente, nem para o mundo que o cerca, mas também medica.

Trazemos aqui algumas discursividades cujas direçóes de sentidos convergem nessa perspectiva: 
Ao preconizar a Política Nacional de Humanização ${ }^{26}$ como eixo transversal às suas ações o Ministério da Saúde reconhece deficiências importantes que comprometem a qualidade da atenção, entre as quais se destaca [...] o predomínio de um modelo de atenção centrado na relação queixa-conduta e no atendimento médico $^{24}$. (p. 208, grifos nossos)

Nos serviços de pronto-atendimento, no modelo centrado na doença, calcado na díade queixa-conduta, o atendimento prestado resume-se a dar uma resposta imediata, visando despachar o mais depressa possível a clientela em função do acúmulo de demanda ${ }^{25}$. (p. 625, grifos nossos)

Considerando a semiologia médica, que tem suas bases nos tempos hipocráticos, a anamnese e o exame físico conduzem ao diagnóstico, que leva ao plano terapêutico e ao prognóstico do paciente. $\mathrm{Na}$ contemporaneidade, o diagnóstico é reduzido ao nome de uma doença e associado, por sua vez, ao nome de um remédio, ou de um conjunto de medicações. Isso permite, a nosso ver, a instalação do tipo de atendimento queixaconduta, no qual o médico reduz a anamnese à queixa do paciente e, sem passar pelo diagnóstico, formula a conduta que, quase invariavelmente, reduz-se à prescrição de um medicamento.

É nesse sentido que indicamos que a redução do diagnóstico a uma classificação e sua evidência como central no atendimento prestado por esse profissional permite, contraditoriamente, que haja a predominância do atendimento queixa-conduta, indicando tal estabilização dessa prática, a ponto de o $\mathrm{MS}^{26}$ afirmar que o atendimento médico no SUS ainda é centrado no tipo queixa-conduta.

Arthur Chioro, então Ministro da Saúde, endossou essa afirmação:

Em nosso país ainda impera o modelo de atendimento queixa-conduta, centrado no procedimento, diagnóstico e na prescrição e muito pouco no cuidado; onde o diagnóstico, o tratamento e a prescrição é muito mais amplo, integral e resolutivo que esse modelo caro e pouco resolutivo que adotamos em nosso país ${ }^{27}$. (grifos nossos)

Para compreendermos essa dinâmica, realizaremos uma análise discursiva do funcionamento do atendimento queixa-conduta focando na determinação sócio-histórica que sustenta essa prática.

Nosso objetivo é o de compreendermos, por meio da $\mathrm{AD}^{6}$, como se dá o atendimento médico dentro desta prática que materializa uma inscrição histórica dos sentidos de uma posição-sujeito médico atravessada pela necessidade (histórico-ideológica) de aplicar uma conduta que, na maioria das vezes, é a prescrição de um fármaco que silencia a formulação do diagnóstico; entendendo que aqui há um duplo silenciamento: aquele reduzido ao nome da doença, à classificação - e que como viemos afirmando, sustentaria a própria possibilidade do funcionamento do atendimento queixa-conduta - e aquele - esse fundamental - que se inscreve em uma memória hipocrática, em que o "conhecer através" é apagado.

Assim, compreendemos que, quando o médico não assume o papel de autor/leitor da sua narração, outro autor/leitor se instala. 
Para nós, este é o ponto nodal de nossa compreensão: este "outro" que se instala no lugar da autoria/leitura do diagnóstico, tal como viemos definindo o que entendemos como diagnóstico - o conhecer através - é o fármaco.

Mendes-Gonçalves ${ }^{28}$ faz consideraçóes a esse respeito, quando afirma:

O achado mais importante é o papel tecnologicamente dominante desempenhado pelo medicamento, muito mais do que um instrumento apenas terapêutico, portanto, na condução da anamnese. [...] A anamnese parece reduzida ao trabalho de selecionar um medicamento, como se a prática 'clínica' consistisse em uma lista quase completa de remédios, para os quais o médico devesse fazer a seleção do cliente: [...] o doente deve ser adequado ao medicamento, sem nunca se colocar a questão da doença, nem enquanto estado, muito menos como processo que resulta de causas que precisam ser obstaculizadas, que se associa a um prognóstico, que ocorre no contexto individual de uma vida concretamente determinada ${ }^{28}$. (p. 104)

Concordamos com esse autor. Embora ele tenha estudado o trabalho médico em centros de saúde, o atendimento queixa-conduta não é exclusivo dos profissionais que lá trabalham. O fármaco - entendido como metáfora da indústria farmacêutica, ou da medicalização da sociedade - interpela o médico, que se desloca de sua narração. É o medicamento que faz parte da condução do atendimento médico quando o profissional não formula o diagnóstico do paciente como um narrador comprometido com o conhecer através, com o processo do adoecimento e, portanto, com o processo de construção de condiçốes que visem à saúde do paciente. O fármaco e aquilo que ele metaforiza (representa) funcionam no fazer dizer do médico, fazem parte do seu discurso, no qual o diagnóstico é silenciado pela sobreposição do fármaco. O medicamento é a resposta pontual à queixa. Ele materializa a conduta: a prescrição. Diríamos que esse tipo de funcionamento é a materialização eficaz de um processo que permitiu o diagnóstico ser reduzido ao nome de uma doença a ponto de sequer mais ser necessário enunciá-la (a doença e, portanto, o diagnóstico assim significado).

Retomamos Porto ${ }^{1}$ para quem o diagnóstico é dito para o mundo que cerca o médico. Para avançar em nossa análise, é preciso que tratemos um pouco dos jogos antecipatórios ${ }^{(\mathrm{k})}$ que fazem parte do funcionamento do discurso. Discursivamente, considera-se que, ao formularmos, fazemos uma antecipação imaginária de nossos interlocutores e de como seremos entendidos por eles. Essa antecipação é feita pelo médico quando ele formula, ou não, o diagnóstico. E o médico tem outro interlocutor, além do paciente, sobre o qual ele também faz uma antecipação do sentido que seria dado a seu discurso por este outro interlocutor: o mundo. É para esse interlocutor, o mundo, que o médico também fala: fala para ele, e para ele presta contas $^{1}$. Qual(is) seria(m) o(s) efeito(s) de sentido de se prestar contas por meio da prescrição medicamentosa? Contas prestadas ao paciente, à sua família, ao estado e suas instituições, à sociedade como um todo.

Nesse jogo de interlocução, é o fármaco que acaba por se interpor. Há uma produção histórico-social na contemporaneidade que produz a evidência da necessidade do fármaco. Esta injunção é tão eficaz que os jogos antecipatórios sustentam (k) Constituem cada tomada de palavra e incidem, conforme Pêcheux (1975) ${ }^{29}$, na projeção imaginária que movimenta a relação entre os interlocutores em termos das imagens que cada um faz de si e do outro (a imagem que eu tenho de meu interlocutor, a imagem que o meu interlocutor tem de mim, a imagem que eu tenho sobre a imagem que meu interlocutor teria de mim, a imagem que eu tenho da imagem que meu interlocutor teria da imagem que eu tenho sobre o meu interlocutor, ad infinitum). 
uma imagem homogênea em torno do remédio que estabiliza a redução da prática médica à prescrição medicamentosa; a redução das necessidades do paciente ao remédio; a redução da responsabilidade médica, perante a sociedade, à prescrição de um medicamento. Nessa evidência, todos são silenciados pelo fármaco: médico, paciente, sociedade e, sobretudo, o processo de adoecimento, suas condiçóes de produção. O fármaco fala pelo médico ao paciente e ao mundo. Diagnóstico e fármaco se equivalem. A queixa é respondida na evidência de que o fármaco desobriga o médico da formulação do diagnóstico, resolve a demanda do paciente, cumpre com sua obrigação perante a sociedade - medicalizada - e mantém a gestão do sistema farmacêutico que, por sua vez, metaforiza a saúde.

Ou seja, as formaçóes imaginárias hegemônicas apontam para a evidência de que o paciente só estará satisfeito, apaziguado, se a ele for receitado um medicamento; esta satisfação é remetida igualmente à sociedade que significa o acesso aos remédios como acesso à saúde. Concomitantemente, é o modo de produção capitalista com toda a gestão do complexo farmacêutico que se coloca na base da injunção à medicação e seu sentido de saúde. O profissional médico é assim interditado a formular o diagnóstico nas outras filiações de sentido que vimos comentando. Esta interdição se dá pelo funcionamento da evidência da necessidade da prescrição do fármaco. Essa evidência é construída ideologicamente na história moderna.

O silêncio do diagnóstico que ocorre no atendimento queixa-conduta é uma forma de o medicamento, e aquilo que ele metaforiza, inscreverem-se no discurso médico. Essa inscrição tem determinação sócio-histórica: envolve o processo de significação inscrito na história política do diagnóstico que vem estreitando-se dentro da formação discursiva biomédica e dentro do imaginário médico construído na atualidade. Esse silêncio interdita a polissemia do diagnóstico, estabilizando sua formulação em torno de o pré-construído ${ }^{(1)}$ de diagnóstico equivaler-se a remédio porque já se equivaleu ao nome de uma doença.

A importância do fármaco, no âmbito do SUS, pode ser percebida neste recorte em que Sônia Fleury ${ }^{30}$ aborda a importância dos medicamentos nos debates parlamentares que antecederam a $8 \underline{\underline{a}}$ Conferência Nacional de Saúde:

[...] na área de medicamentos nós não conseguimos avançar nada. Todos os grupos que participavam da Plenária eram favoráveis a incluir maior controle, a questão dos genéricos, e eu me lembro que o relator da Constituição retirou o item sobre os medicamentos, alegando que havia recebido um telegrama da Abifarma e considerou que isso não tinha importância. Ou seja, esses que eram os mais poderosos sequer nós os enfrentávamos [...] nem apareciam, mandavam telegrama ou faziam o lobby deles sequer nos enfrentando - os grandes poderosos da área de medicamentos, saúde do trabalhador - tudo isso nós perdemos ${ }^{30}$.

Esse acontecimento ocorreu há mais de trinta anos e nós apontamos que a pressão da Indústria Farmacêutica sobre o sistema de saúde se manifesta ainda hoje em duas discursividades: na do médico - por meio da prática clínica sustentada pelo atendimento queixa-conduta e por um diagnóstico reduzido à doença - e na do MS, por meio da política de medicamentos que se manifesta nos gastos crescen-

\footnotetext{
(1) Paul-Henry (2013) aborda sua formulação de pré-construído, afirmando que: "este conceito incide em levar em consideração que "o que se diz, o que se escuta, é sempre atravessado por algo que já foi dito, atravessado por um dito anterior. $\mathrm{O}$ discurso não funciona de modo isolado, ele está sempre ligado a outros discursos que se convocam, que são convocados por sua letra, sua materialidade" (Paul-Henry - entrevista - Jornal da Unicamp, 16-31/12/2013: http:// www.unicamp.br/unicamp/ ju/587/o-discurso-nao-funciona-de-modo-isolado)
} 
tes que o referido Ministério tem com o componente especializado da Assistência Farmacêutica (AF).

Vejamos essa última mais detalhadamente. A AF se constitui por três componentes: a Farmácia Popular, na qual estão incluídos os fármacos mais prescritos nas unidades básicas de saúde; o componente estratégico, do qual fazem parte os fármacos utilizados em programas como os do controle da Tuberculose e o da AIDS; e o componente especializado, no qual estão incluídos os medicamentos que devem ser adquiridos para tratamento especializado e que, muitas vezes, são aqueles comprados pelo Estado após interpelação judicial. Os gastos com fármacos vêm crescendo dentro do SUS, e é no componente especializado que o crescimento é mais acentuado ${ }^{31}$.

É nesta materialidade sócio-histórica que há condições de produção para a estabilização de um atendimento do tipo queixa-conduta, naturalizado para médico e paciente pelo funcionamento ideológico que faz deste atendimento uma evidência. É esta evidência que vem marcando o funcionamento fragmentado do SUS, apontado em vários documentos como uma de suas limitações atuais ${ }^{32}$. $\mathrm{O}$ atendimento queixa-conduta é um atendimento fragmentado, no qual uma peça fundamental não é enunciada: o diagnóstico. É, entretanto, como vimos insistindo, o próprio funcionamento hegemônico de diagnóstico reduzido a uma classificação que permite este apagamento que materializa um outro apagamento: o de um diagnóstico entendido como o processo por meio do qual se "conhece através".

O fármaco, enquanto metáfora da indústria farmacêutica e da medicalização da saúde, atravessa o médico e o SUS e estabiliza a conduta medicamentosa, silenciando o "conhecer através” das condições sócio-históricas em que a doença aconteceu no paciente, e as medidas de prevenção ou de promoção da saúde que seriam adequadas a ele. A conduta do médico, na qual o fármaco assume o lugar do diagnóstico, se dá pela subordinação da conduta à prescrição de um fármaco, em que a função discursiva do médico como autor do diagnóstico é suprimida pelo fármaco.

\section{0 atendimento queixa-conduta: uma análise discursiva do sintagma}

Faremos um gesto de análise a partir da nomeação que este atendimento recebe: queixa-conduta. Há, nesse atendimento, uma associação da queixa do paciente a uma conduta prescrita pelo médico que, frequentemente, é uma prescrição de fármaco. Em um primeiro exercício parafrástico ${ }^{(\mathrm{m})}$, podemos substituir a palavra queixa por outras. Fizemos isso por meio do Dicionário Analógico da Língua Portuguesa, encontrando: descontentamento, aborrecimento, aflição, agrura, desgosto, amargura, desprazer, desconsolo, constrição, padecimento, sofrimento, pesadume, tristeza, enfado, desolação, desagrado, inquietação ${ }^{33}$.

Prosseguindo em nosso exercício parafrástico, substituímos a palavra "conduta" por outra série parafrástica. Os dicionários analógicos nos auxiliaram novamente nessa tarefa. De acordo com Azevedo ${ }^{33}$, a palavra poderia ser substituída por: execução, cumprir, desobrigar-se, orientação e governança.

Refletimos sobre os efeitos de sentido que essa série parafrástica pode produzir. No atendimento queixa-conduta, após a apresentação de algo que incomoda o paciente (uma agrura, um desgosto, uma inquietação) - espaço de sentidos de "queixa” - há, por parte do médico - no espaço de sentidos de "conduta" -, a orientação (m) Os processos parafrásticos são aqueles pelos quais, em todo dizer, há sempre algo que se mantém, isto é, o dizível, a memória. A paráfrase representa, assim, o retorno aos mesmos espaços do dizer. Produzemse diferentes formulações do mesmo dizer sedimentado. A paráfrase está do lado da estabilização. Realizando exercícios parafrásticos o analista do discurso se propõe a compreender como o político e o linguístico se inter -relacionam na constituição dos sujeitos e na produção dos sentidos, ideologicamente assinalados 5 . 
ao consumo de um fármaco; a "execução" de uma condução a um fármaco; o "cumprimento" de lgo $^{(\mathrm{n})}$ ao prescrever um fármaco; a produção da governança de um sistema de fármacos - a indústria farmacêutica; e a possibilidade de desobrigar-se.

Do que a relação queixa-conduta permite desobrigar-se? De nosso lugar discursivo, dizemos: da queixa ao restringi-la a uma resposta pontual e prescritiva; de se responsabilizar junto ao paciente e suas agruras; de formular um diagnóstico, de inserir-se e se responsabilizar pelo processo de construção da saúde.

\section{O silêncio no atendimento queixa-conduta}

Discursivamente, compreendemos que o médico se constitui diferentemente em função de ele formular um diagnóstico ou não, e conforme os sentidos que estão em funcionamento, em sua prática, sobre o diagnóstico (estando ele ausente ou não). Assim, elaborando ou não um diagnóstico, uma relação com seus sentidos é estabelecida. Para nós, aquele que não formula o diagnóstico em sua prática, produz um silenciamento $^{34}$. É sobre isso que é silenciado que discutiremos nas considerações finais.

\section{Considerações finais}

Procuramos, em nosso trajeto, explanar o processo tenso e contraditório em que se instala o funcionamento do atendimento de tipo queixa-conduta, sustentado por uma rede de significação em que o processo de medicalização e o sentido contemporâneo de diagnóstico estão presentes.

Nesse tipo de atendimento, a queixa é pontual, a conduta é pontual e nenhum laço se constitui. Esse laço é pensado em termos do papel social e político do profissional médico de responder, enlaçando-se, ao paciente, à sua família, à sociedade, às instituições do Estado.

O laço não se constitui porque há silenciamento: interdita-se, na contemporaneidade, a formulação do diagnóstico enquanto "o conhecer através" e, assim, o enlace não ocorre seja quando não se formula o diagnóstico, seja quando esse é reduzido a uma classificação, ao nome de uma doença.

O diagnóstico, nessa filiação que vimos defendendo - a do "conhecer através" -, é, pois, para nós, um gesto ético-político do profissional médico. E é seu silenciamento que sustenta as condiçóes de produção de um atendimento queixa-conduta. Ou seja, a redução do diagnóstico a uma nosologia biomédica sustenta a possibilidade de instalação de um atendimento queixa-conduta.

Nesse sentido, lembramos $\operatorname{Tesser}^{22}$, para quem a construção social e epistemológica institucionalizada das verdades diagnósticas (monopolizada pela biomedicina e, cada vez mais, pela indústria científica dos exames complementares e de imagem) e terapêuticas (monopolizada pelos ensaios clínicos controlados e pelas indústrias farmacêuticas) desdobrou-se em processo de relativa alienação ética/ epistemológica e de desresponsabilização social pela missão curadora por parte dos médicos, individualmente.

Assim, consideramos interessante refletir sobre o fato de que o Ministério critica o atendimento queixa-conduta, mas está, contraditoriamente, submetendo a prática médica aqui vigente a este tipo de atendimento subsumido à formação ideológica neoliberal que reduz a saúde à medicalização. (n) Esse pronome indefinido, que produz a dispersão dos sentidos, pode vir a ser preenchido pelo interdiscurso justamente na direção da prescrição dos fármacos: cumpre-se com a responsabilidade junto à Indústria Farmacêutica? 
Ou seja, a necessidade da mudança é apontada ao mesmo tempo em que o funcionamento do Estado se dá na lógica da medicalização, porque se trata de um Estado que está na injunção neoliberal em que são os números (de medicamentos) que produzem a evidência de acesso à saúde, em que o consumo do remédio equivale à saúde, isto é, em que o consumo está na base de constituição da política farmacêutica.

Esta é uma contradição histórica que nos impõe um desafio: como criar condições de produção para que o Estado possa falar de outro lugar que não o do consumo? Esta seria uma condição sine qua non, de nosso ponto de vista, para que seja possível que outras práticas clínicas se estabilizem. Essas outras práticas se distanciariam de uma redução do diagnóstico a uma taxonomia de doenças, viabilizando a construção do diagnóstico como processo de conhecer um indivíduo, através desse próprio indivíduo em suas condiçốes materiais de existência.

\section{Contribuições dos autores}

Todos os autores participaram ativamente de todas as etapas de elaboração do manuscrito.

\section{Agradecimentos}

À CAPES, pela bolsa de estudos concedida a Karla Amorim Sancho.

\section{Direitos autorais}

Este artigo está licenciado sob a Licença Internacional Creative Commons 4.0, tipo BY (https://creativecommons.org/licenses/by/4.0/deed.pt_BR).

\section{Referências}

1. Porto CC. Semiologia médica. Rio de Janeiro: Guanabara Koogan; 1990.

2. Orlandi E. Discurso fundador. Campinas: Pontes; 1993.

3. Orlandi E. Interpretação: autoria, leitura e efeitos do trabalho simbólico. 4 a ed. Campinas: Pontes; 2004.

4. Orlandi E. Análise de discurso: princípios e procedimentos. 11a ed. Campinas: Pontes; 2013.

5. Haroche C, Henry P, Pêcheux M. "La sémantique et la coupure saussurienne: langue, langage, discours”. Langages. 1971;24:93-106 (repris dans Maldidier D). In: Maldidier D. Inquietação do Discurso: (Re)ler Michel Pêcheux hoje. Orlandi EP, tradutor. Campinas: Pontes; 2003.

6. Pêcheux M. O discurso: estrutura ou acontecimento. Orlandi E, tradutor. Campinas: Pontes; 1990.

7. Silva VM. O dicionário e o processo de identificação do sujeito-analfabeto. In: Guimarães ERJ, Orlandi EP. Língua e cidadania: o português no Brasil. Campinas: Pontes; 1996. v. 1, p. 164-76. 
8. Houaiss A. Dicionário Houaiss da língua portuguesa. Rio de Janeiro: Instituto Antônio Houaiss; 2009.

9. Jaeger W. Paideia: los ideales de la cultura griega. Xirau J, Roces W, tradutores. 2a ed. México: Fondo de Cultura Económica;1962.

10. Entralgo LP, organizador. Historia universal de la medicina. Barcelona: Salvat; 1977. La medicina hipocrática.

11. Biggart JH. Cnidos v. Cos. Ulster Med J. 1971; 41(1):1-9.

12. Marques SP. El neohipocratismo. In: Entralgo PL. Historia universal de la medicina. 2a ed. Barcelona: Salvat; 1976. p. 265.

13. Lonie IM. Cos versus Cnidus and the historians: part 2. Hist Sci. 1978; 16:77-92.

14. Sydenham T. La medicine pratique. Francesa MAT, tradutor. Paris: Jault; 1745.

15. Balint GP, Buchanan WW, Dequeker J. A brief history of medical taxonomy and diagnosis. Clin Rheumatol. 2006; 25(2):132-5.

16. Camargo KRD Jr. (Ir)racionalidade médica: os paradoxos da clínica. Physis. 1992; 2(1):203-30.

17. Tesser CD. A verdade na biomedicina, reações adversas e efeitos colaterais: uma reflexão introdutória. Physis. 2007; 17(3):465-84.

18. Camargo KRD Jr. A biomedicina. Physis. 2005; 15 Supl:177-201.

19. Camargo KRD Jr. A construção das doenças na medicina ocidental contemporânea. Rev SBHC.1993; (9):31-40.

20. Descritores em Ciências da Saúde: DeCS [Internet]. São Paulo: BIREME / OPAS / OMS; 2017 [citado 13 Jun 2017]. Disponível em: http://decs.bvsalud.org

21. Rosenberg CE. The Tyranny of diagnosis: specific entities and individual experience. Milbank Q. 2002; 80(2):237-60.

22. Tesser CD. Três consideraçôes sobre a “má medicina”. Interface (Botucatu). 2009; (3)31:273-86.

23. Lana RL. Medicina hipocrática e a semiótica da linguagem na Grécia Antiga. Rev AMRIGS. 2004; 48(4):271-4.

24. Deslandes SF. Humanização dos cuidados em saúde: conceitos, dilemas e práticas. Rio de Janeiro: Fiocruz; 2006.

25. Sucupira AC. A importância do ensino da relação médico-paciente e das habilidades de comunicação na formação do profissional da saúde. Interface (Botucatu). 2007; 11(23):624-7.

26. Ministério da Saúde (BR). Secretaria de Atenção à Saúde. Política Nacional de Humanização. Acolhimento na gestão e o trabalho em saúde. Brasília: Ministério da Saúde; 2006.

27. FEMIPA. 10 desafios para a Saúde brasileira, pelo próprio ministro [Internet]. Curitiba; 2014 [citado 22 Maio 2017]. Disponível em: www.femipa.org.br/ noticias/10-desafios-para-a-saude-brasileira-pelo-proprio-ministro

28. Mendes-Gonçalves RB. Tecnologia e organização social das práticas de saúde. São Paulo: Hucitec; 1994.

29. Pêcheux M. Semântica e discurso: uma crítica à afirmação do óbvio. 4a ed. Orlandi E, tradutor. Campinas: Unicamp; 2009. 
30. Ministério da Saúde (BR). A construção do SUS: história da reforma sanitária e do processo participativo. Brasília, DF: Ministério da Saúde; 2006.

31. Schleifer R, Vannatta J. The logic of diagnosis: peirce, literary narrative, and the history of present illness. J Med Philos. 2006; 31(4):363-84.

32. Onocko-Campos R, Gama CA, Ferrer AL, Santos DVD, Stefanello S, Trapé TL, et al. Saúde mental na atenção primária à saúde: estudo avaliativo em uma grande cidade brasileira. Cienc Saude Colet. 2011; 16(12):4643-52.

33. Azevedo FFS. Dicionário analógico da língua portuguesa: ideias afins / thesaurus. Rio de Janeiro: Lexikon; 2010.

34. Orlandi E. As formas do silêncio: no movimento dos sentidos. Campinas: Unicamp; 1991.

The present paper examines a discursive network between the medicalization process, the discursive functioning of clinical diagnoses in the contemporary world, and a specific functioning of medical practice grounded on a "treat and street" type of care. By developing a discursive analysis, the authors track the history of the word "diagnosis" in an analytical movement that reexamines its conditions of production and functioning at present, making the effects of medicalization explicit. The study addresses "treat and street" care, in which the position-subject physician inserts him/ herself in a production condition so that the drug takes the authorship role in the relationship between physicians and patients, as a consequence of the functioning of diagnosis. This diagnosis functioning in clinical practice implies a silencing of the social and political bond assumed in this practice, which allows the establishment of drugs as a setting of enunciation of the procedures oriented toward care to patients.

Keywords: Speech analysis. Medicalization. Diagnosis. Treat and street. Collective health.

Este artículo hace surgir una red discursiva entre el proceso de medicalización, el funcionamiento discursivo del diagnóstico clínico en la contemporaneidad y un funcionamiento particular de clínica médica sustentado por una atención del tipo queja-conducta. Realizando un Análisis Discursivo, recorrimos movimientos de sentido constitutivo de la historia de la palabra 'diagnóstico', realizando un gesto analítico que retoma sus condiciones de producción y funcionamiento en la actualidad, explicitando efectos de la medicalización. Abordamos la atención queja-conducta, en la cual la posición sujeto médico se insiere en condiciones de producción para que el fármaco asuma el lugar de la autoría en la relación médico-paciente, impactado por el propio funcionamiento del diagnóstico en la actualidad. Resulta que ese funcionamiento del diagnóstico en la práctica clínica implica en un silenciamiento del vínculo social y político supuesto en esa práctica, lo que permite el establecimiento del fármaco como lugar de enunciación de los procedimientos cuyo objetivo es la salud del paciente.

Palabras clave: Análisis de discurso. Medicalización. Diagnóstico. Queja-conducta. Salud Colectiva. 